\title{
Procrastination, Negative Emotional Symptoms, and Mental Well-Being among college students in Saudi Arabia
}

\author{
Elsaeed A. Dardara ${ }^{1, *}$, and Khalid A. Al-Makhalid ${ }^{2}$ \\ 1 Psychology Department, Faculty of Arts, Minia University, Minia 61519 (Egypt) \\ 2 Education \& Psychology Department, Umm Al-Qura University, Makeab (Saudi Arabia)
}

\begin{abstract}
Título: Procrastinación, síntomas emocionales negativos y bienestar mental entre estudiantes universitarios en Arabia Saudita.

Resumen: El objetivo principal del presente estudio fue examinar la relación entre la procrastinación, las emociones negativas y el bienestar mental. Participantes de Arabia Saudita $(n=886$; mujeres 344, 38.8\% y 542 hombres, $\left.61.2 \% ; M_{\text {edad }}=24.33, S D=5.68\right)$. Los participantes completaron cuestionarios en línea sobre la Escala de procrastinación irracional (IPS), las Escalas de estrés por depresión, ansiedad (DASS-21) y el Formulario corto continuo de salud mental (MHC-SF). Según la hipótesis, los hombres postergaron las cosas más que las mujeres. Además, los solteros postergaban más que los casados. Dependiendo de la hipótesis del estudio de que la procrastinación y los síntomas emocionales negativos están relacionados con un peor bienestar mental, la procrastinación está relacionada con niveles más altos de DASS-21 y una disminución del bienestar. Estos hallazgos sugieren que la edad, el género, la depresión, el estrés, la ansiedad y el bienestar eran factores predictivos de la procrastinación. Los hallazgos se suman a la literatura psicológica y mejoran una mejor comprensión de las complicadas asociaciones entre la procastinación, las emociones negativas y el bienestar.

Palabras clave: Procastinación. Síntomas emocionales negativos. DASS21. Bienestar.
\end{abstract}

\section{Introduction}

Procrastination affects all aspects of life (Malobabic, Živković, \& Ranđelović, 2020). Procrastination is the deliberate postponement of duties, even though the postponement is expected to make things worse (Steel, 2007). The intentional postponement of action is known as procrastination, and it is a universal phenomenon (Chu \& Choi, 2005; Tuckman, 1991). Procrastination can occur for many reasons such as postponing an action to avoid stress (Chu \& Choi, 2005), or self-regulatory failure leading to poor well-being (Ferrari \& Díaz-Morales, 2014), and the delay may be due to reaching a goal (Lay, 1986; Steel, Brothen, \& Wambach, 2001). In the past two decades, there has been an extensive increase in the interest in procrastination (Ko \& Chang, 2019). Worldwide, approximately $20 \%$ to $25 \%$ of adolescents and adults suffer from chronic procrastination tendencies in their work and personal lives (Balkis \& Duru, 2007; Ferrari \& Díaz-Morales, 2014; Ko \& Chang, 2019). While, it was reported that 70\% of college students consider themselves academic procrastinators (Schouwenburg, Lay, Pychyl, \& Ferrari, 2004). The relationship between procrastination and health was examined (Steel \& Ferrari, 2013). Furthermore, procrastination was identified as one of the utmost problematic behaviors need-

* Correspondence address [Dirección para correspondencia]: Psychology Department, Faculty of Arts, Minia University, Minia 61519 (Egypt). E-mail: dardarae@mu.edu.eg (Elsaeed Dardara) (Article received: 3-1-2021, revised: 8-4-2021, accepted: 1-6-2021)
Abstract: The main aim of the current study was the examines the relationship between procrastination, Negative Emotions, and mental wellbeing. Participants from Saudi Arabia ( $n=886$; females 344, 38.8\% and 542 males, $\left.61.2 \% ; M_{\text {age }}=24.33, S D=5.68\right)$. Participants completed online questionnaires on the Irrational Procrastination Scale (IPS), the Depression Anxiety Stress Scales (DASS-21), and the Mental Health Continuum-Short Form (MHC-SF). As hypothesized, males procrastinated more than females. Furthermore, single ones procrastinated more than married ones. Depending on the study assumption that procrastination and negative emotional symptoms are related to poorer mental well-being, procrastination is related to higher levels of DASS-21 and decreased well-being. These findings suggest that age, gender, depression, stress, anxiety, and Wellbeing were predictive of procrastination. Findings add to the psychological literature and improve a better comprehension of the complicated associations between Procrastination, Negative Emotions, and Well-Being.

Keywords: Procrastination. Negative Emotional Symptoms. DASS-21. Well-Being. ing enhanced management (Rabin, Fogel, \& Nutter-Upham, 2011; Steel, 2007; Steel \& Ferrari, 2013).

Literature has been interpreted procrastination according to several aspects such as: individual differences (Steel et al., 2001), characteristics of the job (Steel, 2007), motivational aspects (Solomon \& Rothblum, 1984), and demographic variables (Mann, 2016). Previous studies had found a range of personal variables that cause procrastination (Ko \& Chang, 2019), such as procrastination was related to lower-income (Nguyen, Steel, \& Ferrari, 2013); younger procrastinate more than older, males procrastinate more than females, and procrastination is more popular among single and less educated people (Steel \& Ferrari, 2013). However, the results in this area are still inconsistent (Hinsch \& Sheldon, 2013). In addition, many theories have provided explanations for procrastination such as self-worth theory, rational emotive behavior theory, the motivation of achievement theory, and learned powerlessness (Chiu, Chen, Chang, \& Chen, 2020). The selfvalue theory holds that procrastinators may use negative beliefs (Spada, Hiou, \& Nikcevic, 2006), as well as negative emotions (e.g. anxiety, stress, and depression) as psychological self-protection (Flett, Blankstein, \& Martin, 1995; Sirois, 2014; Stöber \& Joormann, 2001).

\section{Procrastination and mental well-being}

Procrastinators find it difficult to maintain and accomplish their personal objectives (Zuber et al., 2020). Procrastination has a negative effect on students' academic success 
and well-being (Atalayin, Balkis, Tezel, \& Kayrak, 2018). Many studies indicated that procrastination is related not only to negative emotions in which the activities are delayed, but it is also related to reduced mental well-being and increased negative emotions (Rozental et al., 2014; Stead, Shanahan, \& Neufeld, 2010; Tice \& Baumeister, 1997). Including depression, anxiety (Glick, Millstein, \& Orsillo, 2014; Haycock, McCarthy, \& Skay, 1998; Steel, 2007), dejection (Lay, 1986), negative life events (Flett et al., 1995), shame (Seo, 2009), poor life satisfaction (Balkis, 2013), and reduced well-being at work (Hen, Goroshit, \& Viengarten, 2021). Also, researchers had shown that procrastination is a trait related to several acute stress associated physical complaints e.g., colds and the flu, digestive problems, insomnia, headaches, and eating disorder (Pychyl \& Sirois, 2016; Sirois, 2007; Sirois, Melia-Gordon, \& Pychyl, 2003). Moreover, procrastination has harmful effects on people's life such as failure to regulate their behavior (Senécal, Koestner, \& Vallerand, 1995), and having higher negative emotional symptoms (Beutel et al., 2016; Rice, Richardson, \& Clark, 2012). Generally in literature participants of the student samples tended to procrastinate and they experienced lower psychological wellbeing, more anxiety, more psychological distress, less emotional ties, less general positive affect, more loss of behavioral and emotional control, and more depressive symptoms (Beswick, Rothblum, \& Mann, 1988; Flett et al., 1995; Moon, Converse, Merlini, \& Vaghef, 2020; Schraw, Wadkins, \& Olafson, 2007; Sirois, 2007; Sirois, 2004; Sirois et al., 2003; Steel, 2007; Steel et al., 2001). A review of the Arabic literature reports a big gap in the assessment of procrastination and its relationship with negative emotional symptoms and mental well-being, particularly in Saudi Arabia.

\section{The current study}

Despite the huge amount of literature on procrastination and its relation to health, the current researchers note a lack of Arabic studies in this field. In this exploratory study, the present study aims to examine the relationships between negative emotional symptoms (depression, anxiety, and stress) and chronic procrastination by exploring the underlying structure of mental well-being (emotional, social, and psychological well-being) among Saudi Arabian undergraduates. Furthermore, the correlations of procrastination with personal characteristics (e.g., age, sex, education, living, income, and marrying) are evaluated. The present study follows Sirois's theory of procrastination and health (Sirois, 2007; Sirois et al., 2003). Procrastination has related to various variables that indicate procrastination is associated with increased stress, depression, anxiety, fatigue, and decreased satisfaction levels (Beutel et al., 2016). This is what the current study wants to verify considering previous studies.

\section{Method}

\section{Participants}

Saudi undergraduate students constituted the not represented sample for the current study $(\mathrm{N}=886 ; 344$ females, $38.8 \%$; 542 males, $61.2 \%$; age $19-35$ years, $\mathrm{M}=24.33, \mathrm{SD}=$ 5.68). from Umm Al-Qura University in Makkah city. Of the total sample, 469 or $52.9 \%$ of them studied applied sciences such as medicine, engineering, and information systems; and 417 or $47.1 \%$ of them studied theoretical subjects (e.g., education, humanities, and administration). The study's main goals were informed to participants through WhatsApp groups, and they volunteered to participate. They were completed online during the 2019-2020 academic year. The procrastination, negative emotional symptoms, and mental wellbeing measures were administered in Arabic after its English versions were translated to the Arabic language. This study was approved by the Deanship of Scientific Research at the Umm Al-Qura University.

\section{Measures}

The Irrational Procrastination Scale (IPS) (Steel, 2010), This measure includes 9 items to measure procrastination. The participants answered all items via a 5 -point fully labeled Likert scale $(1=$ very seldom to $5=$ very often true). The psychometric properties of the English version are reliable with a Cronbach's alpha of .91, and the tool has strong relations with other tools measuring procrastination, ranging from .56 to .87 (Guilera et al., 2018; Steel, 2010). The IPS has several adaptations to other languages and cultures (i.e., Italian, German, Finnish, Polish, Norwegian, Swedish, and Indonesian), and they have been shown to have acceptable psychometric properties in terms of their internal consistency and dimensional structure (Galih Eko, Ide Bagus, \& Hari, 2013; Svartdal, 2017). In the current study, Cronbach's alpha was .89, and Guttman's split-half coefficient was .80. The internal consistency correlations of the items ranged from $r=$ .56 to $r=.82$, where $p<.000$. Furthermore, the IPS scale's concurrent validity has been correlated with the bedtime procrastination scale (Kroese, Ridder, Evers, \& Adriaanse, 2014), $r=.75 p<.000$.

The Depression Anxiety Stress Scales (DASS-21) (Lovibond \& Lovibond, 1995). The DASS-21 was developed for the diagnosis of negative emotional symptoms such as depression, anxiety, and stress (Antony, 1998). The DASS-21 has two forms: the full form contains 42 items, and the short form has 21 items that reflect the same properties as the full form. Participants completed the DASS-21 online form. They reported the symptoms they had experienced over the past month. The DASS-21 has high psychometric properties, and it has been used in many cross-cultural studies (Dahm, Wong, \& Ponsford, 2013; Jun, Johnston, Kim, \& O’Leary, 2018; Norton, 2007; Tran, Tran, \& Fisher, 2013). According to previous studies, The DASS-21 has higher internal con- 
sistency. The alphas ranged from .83 to .87 (Henry \& Crawford, 2005; Osman et al., 2012; Sinclair et al., 2011). In the current study, alpha reliability is .82 for depression, .82 for anxiety, .80 for stress, and .91 for the total DASS-21. Guttman's split-half coefficient was .81 for depression, 85 for anxiety, and .83 for stress. The psychometric properties of the DASS-21 were good. The internal consistency of depression ranged from $r=.77$ to $r=.84$ with $p<.000$, that of anxiety ranged from $r=.78$ to $r=.84$ with $p<.000$, that of stress ranged from $r=.75$ to $r=.76$ with $p<.000$, and that of the total DASS-21 ranged from $r=.85$ to $r=.91$ with $p<$ .000 .

Mental Health Continum-Short Form (MHC-SF). (Keyes, 2006). The MHC-SF has 14 items to measure Social WellBeing (SWB), Psychological Well-Being (PWB), and Emotional Well-Being (EWB). The MHC-SF scale has high internal consistency with alphas ranging from .81 to .91 for three subscales, which represents the subscales' good validity (Keyes et al., 2008; Luijten, Kuppens, van de Bongardt, \& Nieboer, 2019). In the present sample, the Cronbach's alpha reliability indices are .82 for EWB, .80 for SWB, .81 for PWB, and .89 for the total MHC-SF. Spearman-Brown split-half coefficient was .88 for EWB, .90 for SWB, .88 for PWB. These results support the MHC-SF's good construct validity. The internal consistency correlations of the items of EWB ranged from $r=81$ to $r=.85$ with $p<.000$, those of SWB ranged from $r=.69$ to $r=.90$ with $p<.000$. those of PWB ranged from $r=.70$ to $r=.90$ with $p<.000$, and those of the total MHC-SF ranged from $r=.85$ to $r=.90$ with $p$ $<.000$.

\section{Procedures}

First, the original measures of the IPS, DASS, and MHCSF in English were translated into Arabic by the present study authors. Secondly, two native Arabic speakers who were fluent in English translated the English measures into Arabic. Inconsistencies in the initial translations were resolved with the help of a third independent translator. The Arabic versions of the IPS, DASS-21, and MHCSF were then translated back into English by two English-speaking language specialists who were blind to the original scale. The differences between the translated versions were assessed, and a satisfactory agreement with the original IPS, DASS-21, and MHCSF scales was achieved through a consensus of the translators. The finished Arabic measures were checked for Saudi cultural appropriateness by three academics from the Department of English Language at Umm Al-Qura University; controversial issues from the IPS, MHCSF, and DASS21 were identified; and necessary changes were made. The updated measures were re-evaluated by the original panel of experts to finalize the Arabic measures used in this study. The language equivalence, validity, and internal consistency reliability of the IPS, DASS-21, and MHCSF were examined.

\section{Data Analysis Plan}

Statistical analyses were conducted using IBM SPSS 22. To display the differences in procrastination according to personal characteristics, t-tests were used, and to recognize the correlations between procrastination depression, stress, anxiety, and mental well-being, the Pearson correlations were used. The linear regression analysis to predictors of procrastination considering all study variables was also calculated.

\section{Results}

The variables in our study were nearly normally distributed. The results in (Table 1.) display the differences in some personal characteristics such as sex $(p \leq .03)$, residential location $(\phi \leq .000)$, an education level $(\mathrm{P} \leq .000)$, university housing $(p$ $\leq .000)$, and marriage $(\phi \leq .000)$. Males report more procrastination than females; city students are more procrastinate than village students; first-year students are more procrastinate than final year students; students who live alone have more procrastination than those who live with their families who and unmarried students tend to have more procrastination than married couples. The obtained results show that the participants have no significant differences in the academic field, income rate, education achievement, birth rank, and Time spent on the internet.

Table 1

Procrastination according to personal characteristics.

\begin{tabular}{|c|c|c|c|c|c|}
\hline \multicolumn{2}{|l|}{ Variable } & $\mathrm{N}$ & $\mathrm{M}$ & SD & t. $\quad$ Sig. \\
\hline \multirow[t]{2}{*}{ Sex } & Male & 542 & 28.99 & 4.06 & $2.56^{* *} p \leq .01$ \\
\hline & Female & 344 & 28.13 & 4.34 & \\
\hline \multirow{2}{*}{ Academic field } & Theoretical & 255 & 26.36 & 2.76 & $1.01 p \leq .31$ \\
\hline & Applied & 281 & 26.11 & 290 & \\
\hline \multirow{2}{*}{$\begin{array}{l}\text { Residential } \\
\text { location }\end{array}$} & Village & 286 & 26.27 & 3.40 & ${ }^{* * *} \mathrm{p} \leq$ \\
\hline & City & 317 & 27.24 & 2.86 & .000 \\
\hline \multirow[t]{2}{*}{ Income } & High & 414 & 26.70 & 2.98 & $.82 p \leq .40$ \\
\hline & Low & 165 & 26.39 & 2.81 & \\
\hline \multirow[t]{2}{*}{ Education level } & First & 141 & 27.82 & 2.93 & $4.48^{* * *} p \leq .00$ \\
\hline & Final & 160 & 29.34 & 2.90 & \\
\hline \multirow{2}{*}{$\begin{array}{l}\text { Academic } \\
\text { achievement }\end{array}$} & High & 144 & 30.65 & 3.88 & $1.68 p \leq .10$ \\
\hline & Low & 117 & 29.52 & 3.76 & \\
\hline \multirow{2}{*}{$\begin{array}{l}\text { University } \\
\text { housing }\end{array}$} & With family & 471 & 26.72 & 2.69 & $8.26^{* * *} p \leq .000$ \\
\hline & Alone & 138 & 29.12 & 3.87 & \\
\hline \multirow[t]{2}{*}{ Birth rank } & Oldest & 127 & 26.66 & 2.82 & $1.08 p \leq .28$ \\
\hline & Youngest & 334 & 26.35 & 2.73 & \\
\hline \multirow[t]{2}{*}{ Married } & Yes & 430 & 26.50 & 2.96 & $3.67^{* * *} p \leq .00$ \\
\hline & No & 167 & 27.58 & 3.88 & \\
\hline \multirow{2}{*}{$\begin{array}{l}\text { Time spent on } \\
\text { the internet }\end{array}$} & $\leq 8$ hours & 137 & 27.97 & 5.23 & $.99 p \leq .32$ \\
\hline & $\geq 4$ hours & 178 & 27.30 & 3.35 & \\
\hline
\end{tabular}

Results in (Table 2) showed that procrastination more related positively to depression $(r=.23 p<.01)$, followed by stress $(r=.21 p<.01)$, anxiety $(r=.13 p<.01)$, and (total DASS-21) $(r=.22 p<.01)$. The result also shows that procrastination related negatively to EWB $(\mathrm{r}=-.17 p<.01)$, SWB $(\mathrm{r}=-.13 p<.01)$, and Well-being (total) $(\mathrm{r}=-.17 p<.01)$. 
Table 3. shows the multiple regression analysis was performed for the predictors of procrastination, Depression predicted procrastination at $5 \%$ of the variance (Model 1), when well-being was added, the variance increased to $12 \%$ (Model 2), when gender was added, the variance increased to
13\% (Model 3), when stress was added, the variance increased to 14 (Model 4), when anxiety was added, the variance increased to 14 (Model 5), and when age was added, the variance increased to 14 (Model 6).

\section{Table 2}

Correlations between procrastination, depression, stress, anxiety, and mental well-being $(N=886)$.

\begin{tabular}{|c|c|c|c|c|c|c|c|c|c|}
\hline Variable & 1 & 2 & 3 & 4 & 5 & 6 & 7 & 8 & 9 \\
\hline $1 \quad$ Procrastination & - & & & & & & & & \\
\hline Depression & $.23^{*}$ & - & & & & & & & \\
\hline Stress & $.21^{*}$ & $.64^{*}$ & - & & & & & & \\
\hline Anxiety & $.13^{*}$ & $.62^{*}$ & $.78^{*}$ & - & & & & & \\
\hline DASS-21 & $.22^{*}$ & $.85^{*}$ & $.91^{*}$ & $.90^{*}$ & - & & & & \\
\hline Emotional well-being (EWB) & $-.17^{*}$ & $-.52^{*}$ & $-.30^{*}$ & $-.29^{*}$ & $-.42^{*}$ & - & & & \\
\hline Social well-being (SWB) & $-.13^{*}$ & $-.37^{*}$ & $-.18^{*}$ & $-.18^{*}$ & $-.27^{*}$ & $.67^{*}$ & - & & \\
\hline Psychological well-being (PWB) & .03 & $-.47^{*}$ & $-.22^{*}$ & $-.17^{*}$ & $-.32^{*}$ & $.71^{*}$ & $.68^{*}$ & - & \\
\hline Well-being (total) & $-.17^{*}$ & $-.50^{*}$ & $-.25^{*}$ & $-.22^{*}$ & $-.37^{*}$ & $.86^{*}$ & $.90^{*}$ & $.90^{*}$ & - \\
\hline
\end{tabular}

Table 3

Predictors of procrastination.

\begin{tabular}{|c|c|c|c|c|c|c|c|}
\hline Models & $\mathrm{B}$ & SEB & $\beta$ & $t$ & $\mathrm{~F}$ & $R^{2}$ & Adjusted $\mathrm{R}^{2}$ \\
\hline 1 Depression & .15 & .02 & .23 & $7.16^{* * *}$ & $51.32^{* * *}$ & .23 & .05 \\
\hline 2 Depression, and Well-being. & .13 & 0.1 & .30 & $8.48^{* * *}$ & $63.71^{* * *}$ & .36 & .12 \\
\hline 3 Depression Well-being, and Gender. & .88 & .06 & .10 & $3.31^{* * *}$ & $46.61^{* * *}$ & .37 & .13 \\
\hline 4 Depression Well-being, Gender, and stress. & .08 & .03 & .11 & $2.73^{* * *}$ & $37.08^{* * *}$ & .38 & .14 \\
\hline 5 Depression Well-being, Gender stress, and anxiety & .12 & .03 & .17 & $3.39^{* * *}$ & $32.31^{* * *}$ & .39 & .15 \\
\hline 6 Depression Well-being, Gender stress, anxiety, and age. & .06 & .02 & .07 & $2.26^{* *}$ & $27.91^{* * *}$ & .40 & .15 \\
\hline
\end{tabular}

$\frac{6 \text { Depression Well-being }}{* p<.05 ; ;^{* *} p<.01 ; ;^{* * *} p<.001}$

The following variables were not significant in the linear regression analysis: Academic field, residential location, income, education level, academic achievement, university housing, birth rank, marriage, and time on the internet.

In Figure 1 the results of Path analysis evaluating potential directional relations between procrastination and wellbeing(total), showed adequate model fit (CFI $=.67$, TLI $=$
1.7, RMSEA $\left.=.000, \mathrm{R}^{2}=.40\right)$, and no significant cross-lagged effects between procrastination and anxiety $(\beta=-.01, \mathrm{p}=$ $.90)$, where indicated that depression and anxiety were directly associated with well-being, which is an expected result, while procrastination was indirectly associated with wellbeing, where stress has mediated.

Figure 1

Path analysis coefficients for procrastination, Depression, Stress, anxiety, and Well-being.

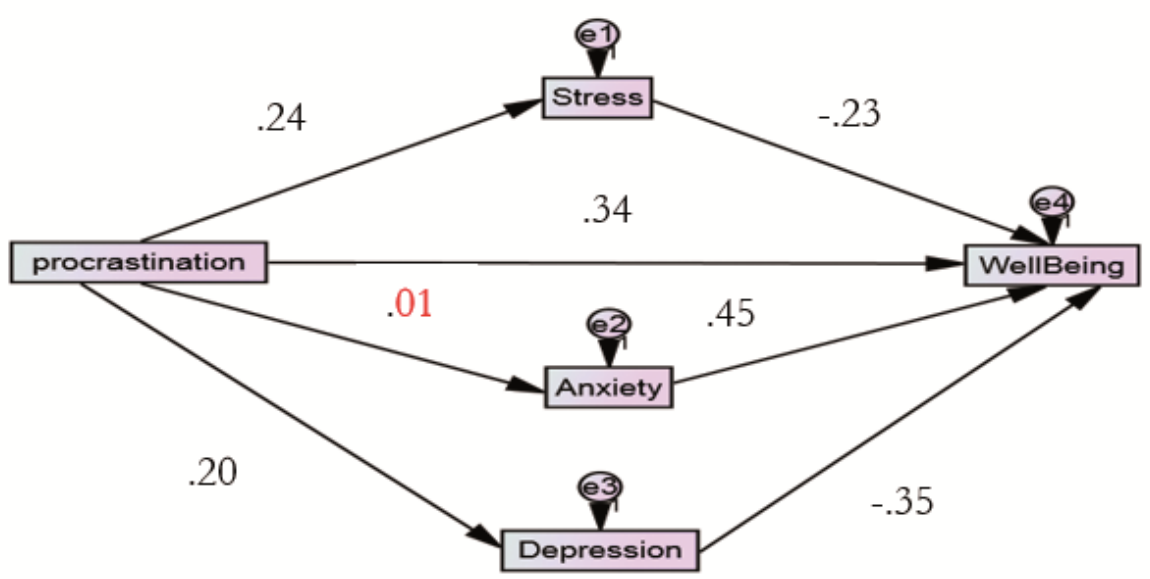




\section{Discussion}

Our results demonstrate that males procrastinate more than girls. This result can be clarified in the light of the collective Saudi culture, where the male is more responsible for selfcare, in addition to his family at the same time, where he has many life requirements toward his family, so he may resort to procrastinate more than female. As researchers have proven that in the male community, males have less emotional control than females (Hofstede \& McCrae, 2004). Also, it can be explained by the terror management theory perspective that males have a greater risk of delaying more than females (Greenberg, Solomon, \& Pyszczynski, 1997; Hirschberger, Florian, Mikulincer, Goldenberg, \& Pyszczynski, 2002). The current research results tend to agree with this theory because it is close to the nature of Arab culture, where the female is exposed to authoritarian socialization patterns. so, females more obedient and disciplined by regulations and carrying out tasks on time without delay. While males' socialization patterns focus on freedom and challenge, in which they have more risk of delaying tasks than females. In contrast to the current study results, that procrastination was higher among Polish females than males (Solomon \& Rothblum, 1984). However, previous results about sexual influences have been inconsistent (Beutel et al., 2016). This may occur in different samples due to different age compositions. Also, the results also showed that new students are more expected to procrastinate than old students. Perhaps the reason is that new students have fewer self-organization and time management skills, especially in the new university environment. This was probably in agreement with another study where new students at the first of the semester showed higher postponement (Baumeister, 2002). Also, students who lived alone showed higher procrastination than those who lived with their families, possibly because family cooperation helps them accomplish tasks. In good agreement with previous studies (Beutel et al., 2016; Özer, Demir, \& Ferrari, 2009; Steel \& Ferrari, 2013). The current result showed that procrastination higher among single students than married students. This result may be explained in the light of the collective Saudi culture, as the married individual gets social support from his family, as well as his wife's family, this may relieve stress and raises the chances of achievement tasks not to procrastinate in compared to an unmarried individual. The current findings contradict several studies that found that procrastination differed depending on age, internet use rate, isolation, income, and education level (Adrian, Lyon, Oti, \& Tininenko, 2010; Nguyen et al., 2013; Schwartz, Côté, \& Arnett, 2005). The contradiction in the obtained results may be explained by the several facets of procrastination. Furthermore, the present research assumptions are harmonious with the literature, where procrastination is related to depression, stress, anxiety, and reduced emotional well-being. The associations between procrastination and well-being have been frequently found to be inversely related and to likely have a reciprocal influence
(DeLongis, Folkman, \& Lazarus, 1988; Hammen, 2004; Stead et al., 2010). Many researchers have explained the correlations of procrastination considering fear of disappointment or automatic and abstract thoughts negatively related to negative reactions such as stress that leading or to accompanying procrastination (Burka \& Yuen, 2008; Flett, Haghbin, \& Pychyl, 2016). The relationship between negative emotions and poor well-being can also be explained by the procrastinators' negative self-assessments (Sirois, Molnar, \& Hirsch, 2015). Other studies also indicated that failing to regulate negative emotions is a major factor in understanding procrastination (Sirois \& Pychyl, 2013; Sirois, 2014). Briefly, the failure to regulate emotions explains the states of negative emotions that are related to the poor emotional wellbeing associated with procrastination. Since the current study is correlational, this does not mean that procrastination is the only reason for negative emotions, and there may be other factors such as postponing health-related behaviors such as exercise, sleep, and health examinations. This may be verified in the future. In addition, as shown in table 2, the correlations within the dimensions of the DASS-21 are very strong, which is evidence of the scale's internal consistency.

The current results of a multiple regression model showed in Table 3 show that the main hypotheses included in our study were supported. For example, the expected predictions between high procrastination and depression, stress, anxiety, and wellbeing were obtained. Furthermore, negative correlations have been found between procrastination and well-being. However, the type of procrastination and improved well-being will additionally support that procrastination can behave as a temporary adaptive buffer to avoid problem-solving issues. However, some studies have shown that students who hesitated at the beginning of a semester reported less stress and fewer symptoms of illness (Martin, Flett, Hewitt, Krames, \& Szanto, 1996; Tice \& Baumeister, 1997). However, at the end of a semester, when deadlines and exams were due, procrastinators suffered from more stress and more symptoms of illnesses (Flett et al., 2016; Sirois, 2014; Stead et al., 2010). The current results strongly agree with previous studies that a poor emotional state is an influencing factor for at-risk students, particularly those who may delay periodic medical examinations (Stead et al., 2010).

To understand procrastination, the results emphasize the importance of focusing on personal aspects. It appears that male and unmarried participants were much more likely to procrastinate, have negative emotions, and have poor mental well-being. Furthermore, the current results give a promising path to future psychological studies to focus in the time organizing skills and self-regulation by choosing these groups when publicizing campus mental health services or by choosing more Umm Al-Qura University students to reduce procrastination and improve mental health by taking into account the characteristics of the collectivism Saudi culture. Overall, the present study results emphasize procrastination as a failure of organizing the priorities, skills, and its relations to psychological well-being. Our study has focused on the 
association between procrastination and various forms of poor psychological well-being, particularly depression, stress, and anxiety. Considering, that procrastination is a personality trait that can lead to exceedingly negative self-concepts and severe adjustment difficulties. The results of the pathway analysis also provide support for the hypothesis that procrastination increases negative emotions (especially depressive stress), which in turn reduces well-being levels. These results are constant with previous studies which reported that confronting procrastination is by mood regulation (Sirois \& Pychyl, 2013). Hence, the current results suggest counseling programs for procrastinator students to improve their emotions.

\section{Study limitations}

The data in our study were collected online, and thus they are self-reported; thus, the results can be regarded as valid for self-measured procrastination but not necessarily valid for observable procrastination behavior (Steel et al., 2001). Psychometrically, this study has difficulties with scales

\section{References}

Adrian, M., Lyon, A. R., Oti, R., \& Tininenko, J. (2010). Developmental Foundations and Clinical Applications of Social Information Processing: A Review. Marriage \& Family Review, 46(5), 327-345. doi:10.1080/01494929.2010.527809

Antony, M. M. (1998). Psychometric properties of the 42-item and 21-item versions of the Depression Anxiety Stress Scales (DASS) in clinical groups and a community sample. Psychol Assess, 10, 176-181.

Atalayin, C., Balkis, M., Tezel, H., \& Kayrak, G. (2018). Procrastination and predictor variables among a group of dental students in Turkey. Psychology, Health \& Medicine, 23(6), 726-732. doi:10.1080/13548506.2017.1418014

Balkis, M. (2013). Academic procrastination, academic life satisfaction and academic achievement: The mediation role of rational beliefs about studying. Journal of Cognitive and Behavioral Psychotherapies, 13(1), 57-74.

Balkis, M., \& Duru, E. (2007). The evaluation of the major characteristics and aspects of the procrastination in the framework of psychological counseling and guidance. Kuram ve Uygulamada Eğitim Bilimleri, 7(1), 376385.

Baumeister, R. F. (2002). Yielding to Temptation: Self-Control Failure, Impulsive Purchasing, and Consumer Behavior. Journal of Consumer Research, 28(4), 670-676. doi:10.1086/338209

Beswick, G., Rothblum, E. D., \& Mann, L. (1988). Psychological antecedents of student procrastination. Australian Psychologist, 23(2), 207217. doi:10.1080/00050068808255605

Beutel, M. E., Klein, E. M., Aufenanger, S., Brähler, E., Dreier, M., Müller, K. W.,... Wölfling, K. (2016). Procrastination, distress and life satisfaction across the age range-A German representative community study. PLOS ONE, 11(2). doi:10.1371/journal.pone.0148054

Burka, J. B., \& Yuen, L. M. (2008). Procrastination: Why You Do It, What to Do About It Now: Hachette Books.

Chiu, S.-I., Chen, T.-Y., Chang, T.-L., \& Chen, C. J. I. J. o. P. R. (2020). Procrastination, dependence and social loafing: comparison in high/low task visibility between active/passive procrastinators. International Journal Psychiatry Research, 3(2), 1-11. doi: 10.33425/26414317.1058

Chu, A. H., \& Choi, J. N. (2005). Rethinking procrastination: positive effects of "active" procrastination behavior on attitudes and performance. $J$ Soc Psychol, 145(3), 245-264. doi:10.3200/socp.145.3.245-264 administered to the students are not validated. Additionally, socially desirable behavior was measured and weakly correlated with procrastination, negative emotional symptoms, and mental well-being. In addition, the present paper sample was not representative enough of Umm Al-Qura University; therefore, so we cannot preclude that people with extreme levels of procrastination have not participated in our study. Accordingly, the results must be generalized with caution. Furthermore, factors such as collectivism and perception of the Arab culture may explain possible connections between procrastination behaviors and well-being. For example, acquiescence response bias to the tendency to agree with the measured items that dominate the collectivist culture.

Acknowledgment: The authors would like to thank Dr. Sirois, F. M. for her valuable suggestion in using the Path analysis method for presenting the data.

Conflict of interest: The authors declare that they have no conflict of interest.

Dahm, J., Wong, D., \& Ponsford, J. (2013). Validity of the Depression Anxiety Stress Scales in assessing depression and anxiety following traumatic brain injury. Journal of Affective Disorders, 151(1), 392-396. doi:https://doi.org/10.1016/j.jad.2013.06.011

DeLongis, A., Folkman, S., \& Lazarus, R. S. (1988). The impact of daily stress on health and mood: Psychological and social resources as mediators. Journal of Personality and Social Psychology, 54(3), 486-495. doi:10.1037/0022-3514.54.3.486

Ferrari, J. R., \& Díaz-Morales, J. F. (2014). Procrastination and mental health coping: A brief report related to students. Individual Differences Research, 12(1), 8-11.

Flett, A. L., Haghbin, M., \& Pychyl, T. A. (2016). Procrastination and Depression from a Cognitive Perspective: An Exploration of the Associations Among Procrastinatory Automatic Thoughts, Rumination, and Mindfulness. Journal of Rational-Emotive \& Cognitive-Behavior Therapy, 34(3), 169-186. doi:10.1007/s10942-016-0235-1

Flett, G. L., Blankstein, K. R., \& Martin, T. R. (1995). Procrastination, negative self-evaluation, and stress in depression and anxiety: A review and preliminary model. In Procrastination and task avoidance: Theory, research, and treatment. (pp. 137-167). New York, NY, US: Plenum Press.

Galih Eko, P., Ide Bagus, S., \& Hari, K. L. (2013). Validasi Alat Ukur Irrational Procrastination Scale (IPS). Calyptra, 2(1).

Glick, D. M., Millstein, D. J., \& Orsillo, S. M. (2014). A preliminary investigation of the role of psychological inflexibility in academic procrastination. Journal of Contextual Behavioral Science, 3(2), 81-88. doi:https://doi.org/10.1016/j.jcbs.2014.04.002

Greenberg, J., Solomon, S., \& Pyszczynski, T. (1997). Terror Management Theory of Self-Esteem and Cultural Worldviews: Empirical Assessments and Conceptual Refinements. In M. P. Zanna (Ed.), Advances in Experimental Social Psychology (Vol. 29, pp. 61-139): Academic Press.

Guilera, G., Barrios, M., Penelo, E., Morin, C., Steel, P., \& Gómez-Benito, J. (2018). Validation of the Spanish version of the Irrational Procrastination Scale (IPS). PLOS ONE, 13(1), e0190806. doi:10.1371/journal.pone.0190806

Hammen, C. (2004). Stress and Depression. Annual Review of Clinical Psychology, 1(1), 293-319. doi:10.1146/annurev.clinpsy.1.102803.143938

Haycock, L. A., McCarthy, P., \& Skay, C. L. (1998). Procrastination in College Students: The Role of Self-Efficacy and Anxiety. Journal of 
Counseling Development, 76(3), 317-324. doi:https://doi.org/10.1002/j.1556-6676.1998.tb02548.x

Hen, M., Goroshit, M., \& Viengarten, S. (2021). How decisional and general procrastination relate to procrastination at work: An investigation of office and non-office workers. Personality and Individual Differences, 172, 110581. doi:https://doi.org/10.1016/j.paid.2020.110581

Henry, J. D., \& Crawford, J. R. (2005). The short-form version of the Depression Anxiety Stress Scales (DASS-21): Construct validity and normative data in a large non-clinical sample. British Journal of Clinical Psychology, 44(2),

227-239. doi:https://doi.org/10.1348/014466505X29657

Hinsch, C., \& Sheldon, K. M. (2013). The impact of frequent social Internet consumption: Increased procrastination and lower life satisfaction. Journal of Consumer Behaviour, 12(6), 496-505. doi:https://doi.org/10.1002/cb.1453

Hirschberger, G., Florian, V., Mikulincer, M., Goldenberg, J. L., \& Pyszczynski, T. (2002). GENDER DIFFERENCES IN THE WILLINGNESS TO ENGAGE IN RISKY BEHAVIOR: A TERROR MANAGEMENT PERSPECTIVE. Death Studies, 26(2), 117-141. doi:10.1080/074811802753455244

Hofstede, G., \& McCrae, R. R. (2004). Personality and Culture Revisited: Linking Traits and Dimensions of Culture. Cross-Cultural Research, 38(1), 52-88. doi:10.1177/1069397103259443

Jun, D., Johnston, V., Kim, J.-M., \& O’Leary, S. (2018). Cross-cultural adaptation and validation of the Depression, Anxiety and Stress Scale21 (DASS-21) in the Korean working population. Work, 59, 93-102. doi:10.3233/WOR-172661

Keyes, C. L. M. (2006). The Subjective Well-Being of America's Youth: Toward a Comprehensive Assessment. Adolescent \& Family Health, 4(1), 3-11

Keyes, C. L. M., Wissing, M., Potgieter, J. P., Temane, M., Kruger, A., \& van Rooy, S. (2008). Evaluation of the mental health continuum-short form (MHC-SF) in setswana-speaking South Africans. Clinical Psychology \& Psychotherapy, 15(3), 181-192. doi:https://doi.org/10.1002/cpp.572

Ko, C.-Y. A., \& Chang, Y. (2019). Investigating the Relationships Among Resilience, Social Anxiety, and Procrastination in a Sample of College Students. Psychol Rep, 122(1), 231-245. doi:10.1177/0033294118755111

Kroese, F., Ridder, D. D. d., Evers, C., \& Adriaanse, M. J. F. i. P. (2014). Bedtime procrastination: introducing a new area of procrastination. 5 .

Lay, C. H. (1986). At last, my research article on procrastination. Journal of Research in Personality, 20(4), 474-495. doi:https://doi.org/10.1016/0092-6566(86)90127-3

Lovibond, P. F., \& Lovibond, S. H. (1995). The structure of negative emotional states: Comparison of the Depression Anxiety Stress Scales (DASS) with the Beck Depression and Anxiety Inventories. Behaviour Research and Therapy, 33(3), 335-343. doi:https://doi.org/10.1016/00057967(94)00075-U

Luijten, C. C., Kuppens, S., van de Bongardt, D., \& Nieboer, A. P. (2019). Evaluating the psychometric properties of the mental health continuum-short form (MHC-SF) in Dutch adolescents. Health and Ouality of Life Outcomes, 17(1), 157. doi:10.1186/s12955-019-1221-y

Malobabic, M., Živković, D., \& Ranđelović, N. (2020). THE SEVERITY OF PSYCHOSOMATIC PROBLEMS AND PROCRASTINATION IN STUDENTS. Facta Universitatis, Series: Teacbing, Learning and Teacher Education $3(2)$, doi:https://doi.org/10.22190/FUTLTE1902109M

Mann, L. (2016). Procrastination revisited: A commentary. Australian Psychologist, 51(1), 47-51. doi:10.1111/ap.12208

Martin, T. R., Flett, G. L., Hewitt, P. L., Krames, L., \& Szanto, G. (1996). Personality correlates of depression and health symptoms: A test of a self-regulation model. Journal of Research in Personality, 30(2), 264-277. doi:10.1006/irpe.1996.0017

Moon, N. A., Converse, P. D., Merlini, K. P., \& Vaghef, K. (2020). The role of off-task thoughts and behaviors in linking self-control with achievement-related and well-being outcomes. Journal of Research in Personality, 86, 103935. doi:https://doi.org/10.1016/j.jrp.2020.103935

Nguven, B., Steel, P., \& Ferrari, J. R. (2013). Procrastination's Impact in the Workplace and the Workplace's Impact on Procrastination. International Journal of Selection and Assessment, 21(4), 388-399. doi:https://doi.org/10.1111/ijsa.12048
Norton, P. J. (2007). Depression Anxiety and Stress Scales (DASS-21): Psychometric analysis across four racial groups. Anxiety, Stress, \& Coping, 20(3), 253-265. doi:10.1080/10615800701309279

Osman, A., Wong, J. L., Bagge, C. L., Freedenthal, S., Gutierrez, P. M., \& Lozano, G. (2012). The Depression Anxiety Stress Scales-21 (DASS21): Further Examination of Dimensions, Scale Reliability, and Correlates. Journal of Clinical Psychology, 68(12), 1322-1338. doi:https://doi.org/10.1002/jclp.21908

Özer, B. U., Demir, A., \& Ferrari, J. R. (2009). Exploring Academic Procrastination Among Turkish Students: Possible Gender Differences in Prevalence and Reasons. The Journal of Social Psychology, 149(2), 241257. doi:10.3200/SOCP.149.2.241-257

Pychyl, T. A., \& Sirois, F. M. (2016). Chapter 8 - Procrastination, Emotion Regulation, and Well-Being. In F. M. Sirois \& T. A. Pychyl (Eds.), Procrastination, Health, and Well-Being (pp. 163-188). San Diego: Academic Press.

Rabin, L. A., Fogel, J., \& Nutter-Upham, K. E. (2011). Academic procrastination in college students: The role of self-reported executive function. Journal of Clinical and Experimental Neuropsychology, 33(3), 344357. doi:10.1080/13803395.2010.518597

Rice, K. G., Richardson, C. M. E., \& Clark, D. (2012). Perfectionism, procrastination, and psychological distress. Journal of Counseling Psycbology, 59(2), 288-302. doi:10.1037/a0026643

Rozental, A., Andersson, G., Boettcher, J., Ebert, D. D., Cuijpers, P., Knaevelsrud, C., . . . Carlbring, P. (2014). Consensus statement on defining and measuring negative effects of Internet interventions. $\begin{array}{lll}\text { Internet } & \text { Interventions, } & 1(1),\end{array}$ doi:https://doi.org/10.1016/j.invent.2014.02.001

Schouwenburg, H. C., Lay, C. H., Pychyl, T. A., \& Ferrari, J. R. (2004). Counseling the procrastinator in academic settings: American Psychological Association.

Schraw, G., Wadkins, T., \& Olafson, L. (2007). Doing the things we do: A grounded theory of academic procrastination. Journal of Educational Psychology, 99(1), 12-25. doi:10.1037/0022-0663.99.1.12

Schwartz, S. J., Côté, J. E., \& Arnett, J. J. (2005). Identity and Agency in Emerging Adulthood: Two Developmental Routes in the Individualization Process. Youth \& Society, 37(2), 201-229. doi:10.1177/0044118X05275965

Senécal, C., Koestner, R., \& Vallerand, R. J. (1995). Self-Regulation and Academic Procrastination. The Journal of Social Psychology, 135(5), 607619. doi:10.1080/00224545.1995.9712234

Seo, E. H. (2009). The relationship of procrastination with a mastery goal versus an avoidance goal. Social Behavior and Personality: An International Journal, 37(7), 911-920. doi:10.2224/sbp.2009.37.7.911

Sinclair, S. J., Siefert, C. J., Slavin-Mulford, J. M., Stein, M. B., Renna, M., \& Blais, M. A. (2011). Psychometric Evaluation and Normative Data for the Depression, Anxiety, and Stress Scales-21 (DASS-21) in a Nonclinical Sample of U.S. Adults. Evaluation \& the Health Professions, 35(3), 259-279. doi:10.1177/0163278711424282

Sirois. (2007). "I'll look after my health, later": A replication and extension of the procrastination-health model with community-dwelling adults. Personality and Individual Differences, 43(1), 15-26. doi:https://doi.org/10.1016/j.paid.2006.11.003

Sirois, F., \& Pychyl, T. (2013). Procrastination and the Priority of ShortTerm Mood Regulation: Consequences for Future Self. Social and $\begin{array}{llll}\text { Personality Psychology } \quad \text { Compass, } & 7(2), & 115-127 .\end{array}$ doi:https://doi.org/10.1111/spc3.12011

Sirois, F. M. (2004). Procrastination and intentions to perform health behaviors: The role of self-efficacy and the consideration of future consequences. Personality and Individual Differences, 37(1), 115-128. doi:https://doi.org/10.1016/i.paid.2003.08.005

Sirois, F. M. (2014). Procrastination and Stress: Exploring the Role of Selfcompassion. Self and Identity, 13(2), 128-145. doi:10.1080/15298868.2013.763404

Sirois, F. M., Melia-Gordon, M. L., \& Pychyl, T. A. (2003). "I'll look after my health, later": an investigation of procrastination and health. Personality and Individual Differences, 35(5), 1167-1184. doi:https://doi.org/10.1016/S0191-8869(02)00326-4 
Sirois, F. M., Molnar, D. S., \& Hirsch, J. K. (2015). Self-Compassion, Stress, and Coping in the Context of Chronic Illness. Self and Identity, 14(3), 334-347. doi:10.1080/15298868.2014.996249

Solomon, L. J., \& Rothblum, E. D. (1984). Academic procrastination: Frequency and cognitive-behavioral correlates. Journal of Counseling Psychology, 31(4), 503-509. doi:10.1037/0022-0167.31.4.503

Spada, M. M., Hiou, K., \& Nikcevic, A. V. (2006). Metacognitions, Emotions, and Procrastination. Journal of Cognitive Psychotherapy, 20(3), 319-326. doi:10.1891/jcop.20.3.319

Stead, R., Shanahan, M. J., \& Neufeld, R. W. J. (2010). "I'll go to therapy, eventually": Procrastination, stress and mental health. Personality and Individual Differences, $\quad 49(3), \quad 175-180$. doi:https://doi.org/10.1016/j.paid.2010.03.028

Steel, P. (2007). The nature of procrastination: A meta-analytic and theoretical review of quintessential self-regulatory failure. Psychological Bulletin, 133(1), 65-94. doi:10.1037/0033-2909.133.1.65

Steel, P. (2010). Arousal, avoidant and decisional procrastinators: Do they exist? Personality and Individual Differences, 48(8), 926-934. doi:https://doi.org/10.1016/j.paid.2010.02.025

Steel, P., Brothen, T., \& Wambach, C. (2001). Procrastination and personality, performance, and mood. Personality and Individual Differences, 30(1), 95-106. doi:https://doi.org/10.1016/S0191-8869(00)00013-1

Steel, P., \& Ferrari, J. (2013). Sex, Education and procrastination: An epidemiological study of procrastinators' characteristics from a global sample. European Journal of Personality, 27(1), 51-58. doi:10.1002/per.1851

Stöber, J., \& Joormann, J. (2001). Worry, procrastination, and perfectionism: Differentiating amount of worry, pathological worry, anxiety, and depression. Cognitive Therapy and Research, 25(1), 49-60. doi:10.1023/A:1026474715384

Svartdal, F. (2017). Measuring procrastination: Psychometric properties of the Norwegian versions of the Irrational Procrastination Scale (IPS) and the Pure Procrastination Scale (PPS). Scandinavian Journal of Educational Research, 61(1), 18-30. doi:10.1080/00313831.2015.1066439

Tice, D. M., \& Baumeister, R. F. (1997). Longitudinal Study of Procrastination, Performance, Stress, and Health: The Costs and Benefits of Dawdling. Psychological Science, 8(6), 454-458. doi:10.1111/j.1467-9280.1997.tb00460.x

Tran, T. D., Tran, T., \& Fisher, J. (2013). Validation of the depression anxiety stress scales (DASS) 21 as a screening instrument for depression and anxiety in a rural community-based cohort of northern Vietnamese women. BMC Psychiatry, 13(1), 24. doi:10.1186/1471-244X$13-24$

Tuckman, B. W. (1991). The Development and Concurrent Validity of the Procrastination Scale. Educational and Psychological Measurement, 51(2), 473-480. doi:10.1177/0013164491512022

Zuber, S., Cauvin, S., Haas, M., Daviet, A.-S., Da Silva Coelho, C., \& Kliegel, M. (2020). Do self-reports of procrastination predict actual behavior? , 29(4), e1843. doi:https://doi.org/10.1002/mpr.1843 